\title{
Tectonic process analysis in Zagros Mountain with the aid of drainage networks and topography maps dated 1950-2001 in GIS.
}

\begin{abstract}
In this study, a digital elevation model was used for hydrological study/watershed management, topography, geology, tectonic geomorphology, and morphometric analysis. Geographical information system provides a specialized set of tools for the analysis of topography, watersheds, and drainage networks that enables to interpret the tectonic activities of an area. The drainage system maps of Zagros Mountains in southwest Iran have been produced using multi-temporal datasets between 1950 and 2001 to establish the changes between geomorphic signatures and geomorphic aspect during time and to correlate them with recent neo-tectonics. This paper discusses the role of drainage for interpreting the scenario of the tectonic processes as one of important signatures. The study shows variation in drainage network derived from topography maps. Thus, changes in drainage pattern, stream length, stream gradient, and the number of segment drainage order from 1950 to 2001 indicate that Zagros Mountain has been subjected to recent neo-tectonic processes and emphasized to be a newly active zone.
\end{abstract}

Keyword: Tectonic analysis; Remote sensing; GIS; Zagrous Mountain. 